\title{
Resource-Type Descriptions For School Library Resources: Australian and New Zealand school library staff prefer user- friendly classifications to RDA and GMD vocabularies
}

\author{
Ben Chadwick, Ph.D. \\ Education Services Australia, Australia
}

\begin{abstract}
Descriptions of resource type assist students to discover resources. Under AACR2, bibliographic records contained the general material designation as a "first stop" in identifying typeness. Under RDA three controlled vocabularies describe content, media and carrier type. These went some way to address criticisms of GMD, however the language of the RDA terms is criticised as being unintuitive to users, and dispersing the description over three facets presents its own problems. In this context, libraries struggle to decide how to represent typeness to their end-users (Ou \& Saxon, 2014). The Schools Catalogue Information Service (SCIS) provides high quality, consistent MARC records to schools internationally, including over $93 \%$ of Australian schools. SCIS ceased cataloguing of GMD in 2017 after four years of cataloguing records containing both GMD and RDA values. In 2016, SCIS surveyed 1212 Australian and New Zealand school library staff as a first stage in researching an alternative vocabulary incorporating user-friendly type (UFT) terminology. Results indicate that school library staff preferred UFTs to GMD and RDA terms and, where applicable, preferred terms where resource format is qualified in parentheses.
\end{abstract}

\section{Keywords: Resource Type, GMD, RDA, Descriptive Metadata, School Libraries}

\section{INTRODUCTION}

"What types of resources do you have in your school library?"

Typeness is an intuitive and ubiquitous quality of bibliographic resources, used to assist in finding, identifying, selecting, and locating resources. However, library records often describe typeness through a range of controlled and uncontrolled vocabularies, some of which do not offer intuitive and user-friendly descriptions appropriate to the school library (eg Hider, 2009; Panchyshyn, 2014).

The Schools Catalogue Information Service (SCIS) (http://www2.curriculum.edu.au/scis/home.html) creates bibliographic data for educational and literacy resources used in schools, and offers a subscription service providing access to its database of almost 1.5 million records. Subscribers, including almost $94 \%$ of Australian schools, import SCIS's MARC-21 records into their local library systems. In 2017 SCIS is undertaking a full revision of its online services, part of which includes exploring best-practices for discoverability of resources according to their various types.

In early 2016, SCIS conducted a survey of Australian and New Zealand school libraries, aimed at better understanding the kinds of resources held in modern schools and school libraries, and how they are described and organised. This paper presents initial analyses of that survey data aimed at examining the terminology respondents feel best describes some contemporary resource types for their end-users.

In the modern school library, just as in the modern classroom, teachers and learners have access to a wide variety of resources, from print and audio-visual to the ever expanding array of digital formats, including websites, apps, digital video, interactive learning and reference resources, e-books, eaudiobooks and e-textboooks (Oddone, 2011; O'Connell , Bales, \& Mitchell, 2015; Domingo \& Gargante, 2016). In 2016, SCIS subscribers accessed records for a wide variety of resources besides hard-copy books, including digital video, e-books, websites, DVDs, kits, activity cards and flash cards, digital databases, mobile apps, audiobooks (online and $\mathrm{CD}$ ), hardcopy games, music notation, posters and charts, music CDs, maps, and toys (Chadwick, 2017). Records for digital resources constituted $12.3 \%$ percent of downloads. The Australian Library Industry Associations (ALIA) projects that by 2020 Australian 
libraries will hold a 80:20 ratio of hardcopy to e-books (ALIA, 2015), and a 2016 estimate suggests that rates are on a steady increase, with approximately $33 \%$ of schools having purchased an e-book in the prior year (Softlink, 2016).

Whilst the question posed at the head of this section is instinctively straightforward, describing the typeness of these kinds of resources presents technical challenges. Carlyle (1999) stated that "ideally, information retrieval systems will reflect users' perceptions and expectations, so that the information presented to them is understandable, and responds effectively to their needs" (p. 185). In her analysis of user's conceptualisation of library resource groupings, Carlyle found that while physical format was most prominent, respondents also utilised audience, content, pictorial elements, usage/purpose, and language in their classification judgements. In Hider's 2009 study of user's classifications of resource type, the multifaceted nature of user's understanding of typeness was also apparent: typeness included the format and content of the resource, but extended beyond these to incorporate properties such as mode of issuance, purpose, subject, audience, and extent.

In bibliographic metadata, controlled vocabularies tend to break typeness down along some of these dimensions. For example, in the online environment the Dublin Core metadata schema (http://dubincore.org) offers elements such as format and type, with recommended controlled vocabularies including the MIME Internet Media Types (http://www.iana.org/assignments/media-types) and DCMI Type Vocabulary (http://dublincore.org/documents/dcmi-type-vocabulary/).

Within the MARC-21 records of the library community, typeness is represented in multiple elements, using both uncontrolled values and a range of controlled vocabularies (Ou \& Saxon, 2014). In MARC control fields (http://loc.gov/marc/bibliographic), such as the Leader, 008 and 007, type is represented as controlled values for properties including content (such as in Leader positions 06 , and 008 positions 24 to 27 for books), issuance (Leader positions 07), form and format (such as 007 position 00 to 01, and 008 position 23) and, for some resource types, target audience (008 position 22).

When the Resource Description and Access (RDA) cataloguing standard succeeded the AngloAmerican Cataloguing Rules, Second Edition (AACR2), the repeatable MARC variable fields 336, 337 and 338 were introduced to represent the type properties of content, media, and carrier, respectively. These fields are populated by values from their respective RDA controlled vocabularies (http://rdatoolkit.org). Hider (2009) notes that media type and carrier type sit within a hierarchy, with the various carrier formats organised within the intermediating device defined by media type. For example, a video disc (carrier) requires a video device (media) whereas an audio disc (carrier) requires an audio device (media). Green and Fallgren (2007) recognised that whilst content type appears to be orthogonal to media and carrier type, they are in fact enmeshed because some content types are, and can only be, expressed via certain media formats. For example, a three-dimensional moving image is not expressed via audio media, and spoken word is not expressed via microform.

Under AACR2, the General Material Designation (GMD) was a single value placed in the MARC 245 Title Statement "to indicate, in general terms and at an early point in the description, the class of materials to which the item belongs" (Guerrini, 2004). The GMD value was drawn from a brief, flat controlled vocabulary to help the user distinguish items in the same catalogue according to their differing modes of expression (Guerrini, 2004). These values did not systematically represent typeness along dimensions such as content and format, though they strongly reflected the physical carrier of the item and incorporated properties such as intellectual/artistic content and form of expression (Guerrini, 2004).

Use of the GMD, MARC control fields and RDA vocabularies in bibliographic records is not consistent over time and will rarely be consistent within collections, and values from one vocabulary can not be easily mapped to another (Panchyshyn, 2014). AACR2 records contain both MARC control fields and the GMD, RDA records contain the MARC control fields and RDA type fields, and hybrid records may contain each of these (Ou \& Saxon, 2014). Considerations around the deprecation of MARC raises the possibility of records containing only the RDA fields, possibly with combinations of as-yet unspecified vocabularies. Even within these 'generations' of records, different type encodings will be applied with differing degrees of consistency. 
Despite these various ambiguities and representations, typeness as a construct plays a prominent role in the user tasks of finding, identifying, selecting, and locating resources. Many collections are organised by type (Carlyle, 1999), including aspects of format (such as the print, audio-visual, and online collections), content (music CDs versus audiobook CDs; reference material versus general fiction and non-fiction), audience (children's and young adult fiction; teacher resources), and issuance (periodicals, collections of series, and monographs). For the user, type is an early and immediate indication of where an item may be physically located or whether it can be accessed from the computer they are on.

Typeness is ubiquitous in online catalogue interfaces. Figure 1 displays how type is represented in major Australian and international systems to limit both basic and advanced searches, as a search index per se, and as a facet to limit results. It is such a prominent dimension that it is often the primary feature organising search (eg see the tabs in WorldCat's basic search in Figure 1A) and result sets (see the 'Bento Box' style of Trove's result sets, organised by type http://trove.nla.gov.au/).

In Niu, Zhang, and Chen's (2014) study of usage of the VuFind and Primo systems in an academic library, a resource type was specified in $11.8 \%$ of searches on Primo. Format was the most used facet in VuFind and the second most used in Primo, however the most used facet, "Show Only", included representations of typeness including Online resources.

Typeness is also prominent in the search behavior of library staff. On the SCIS catalogue, type was the most prominent dimension on which basic searches were limited (13\% of searches), followed by year of publication at only $2 \%$ of searches and place of publication $(0.3 \%)$. In advanced search, dimensions of type were also the most prominent search limits with $19 \%$ of searches limited by format and $5 \%$ by content type (Chadwick, 2017).

Typeness is central to some of the core selection decisions faced by end-users. For example, it indicates the equipment requirements of the resource which, depending on equipment availability, may influence a user's decision to utilise the resource. It also informs user decisions around resource utilisation on the basis of modality preferences or capabilities -- some users may prefer using audio to written text whilst others may be precluded from using written text.

Typeness also plays a role in the identification process, enabling users to distinguish two records representing the same work by the differing formats in which they are manifested. As mentioned above, this was the intended purpose of the General Material Designation (GMD) under AACR2. 


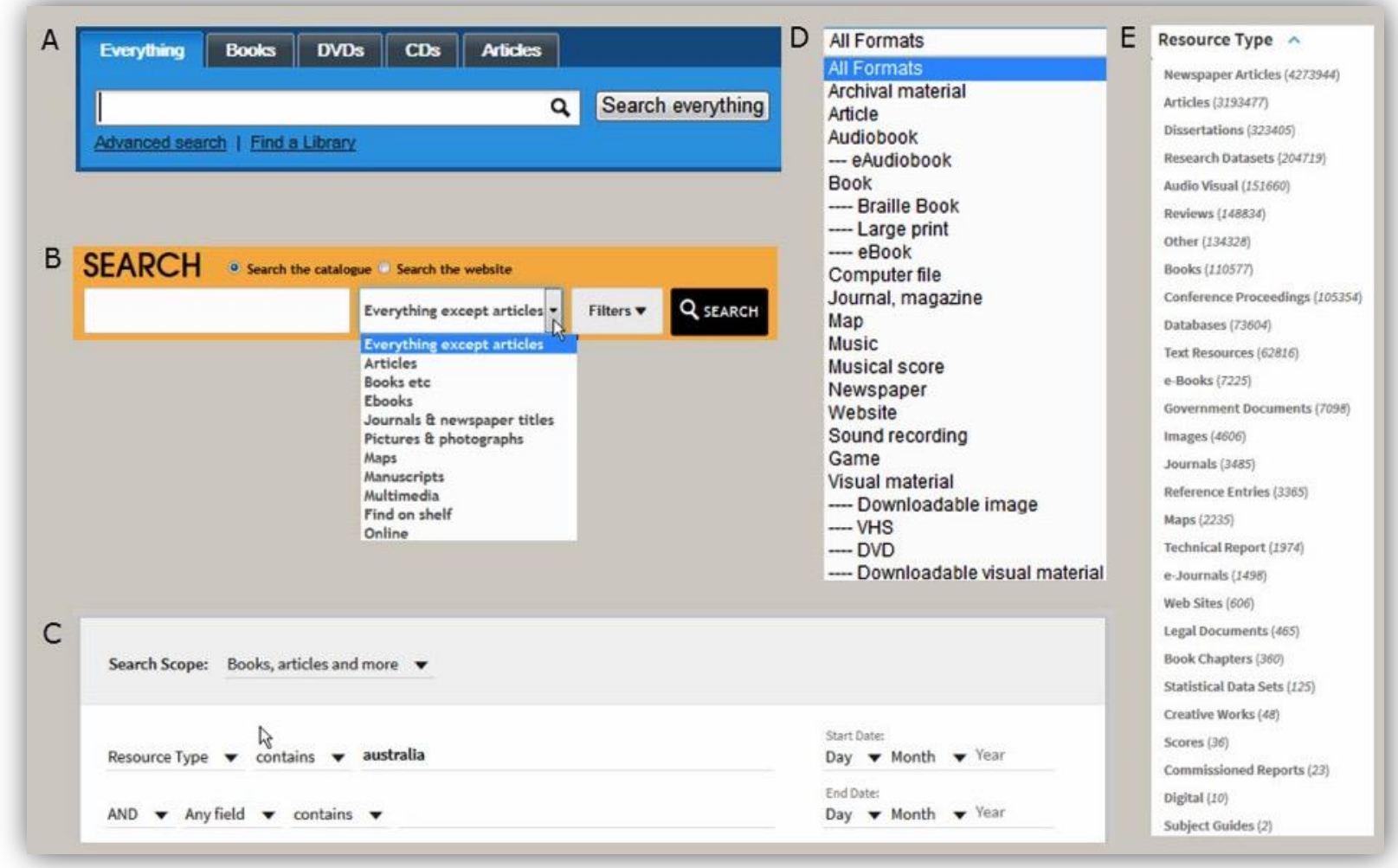

Figure 1 Resource Type represented in WorldCat's (A) basic search and (D) advance search filter, (B) the State Library of Victoria's basic search filter, (C) RMIT's advanced search, (E) and Trove's faceting

The GMD's decommissioning under RDA was due to the widely held opinion that its controlled values were imprecise and unhelpful to users - an issue that became pronounced with the proliferation of electronic formats (Ou \& Saxon, 2014). The GMD values irreconcilably conflated format and content for some resource types (Hider, 2009), which was especially problematic for digital resources such as an MP3 musical recording, which could be represented as "Electronic Resource" or "Sound recording."

Whilst the multidimensional approach of the RDA fields is intended to address these shortcomings of the GMD, the multiple repeatable facets of RDA present their own problems (Ou \& Saxon, 2014). Hider (2009) noted that "two facets [of RDA content and carrier] are not very intuitive for many end users" (p. 113), possibly reflecting the fact that such dimensions are dictated by cataloguing standards and OPAC displays rather than user's inherent conceptualisations. Hider (2009b) concludes that description based on just content or carrier "would fall a long way short of optimal, and even both lists, in combination, would fall considerably short" (p. 558).

Whether and how to display these fields is not clear to libraries or systems. As of Ou \& Saxon's 2014 survey of 53 academic, law, public and special libraries, 62\% did not display any of the RDA fields, $26 \%$ displayed all three, four displayed 336 and 338 but not 337, and one each displayed 336 and 338 only. Ten of the respondents added RDA fields to their AACR2 records, and at least three added GMD to their RDA records.

Panchyshyn (2014) recognised the importance of providing consistent display of type descriptions across AACR2, hybrid, and RDA records, and explored a "quick and inexpensive solution that would allow [OhioLINK] libraries to compensate for the loss of the GMD" (p. 495). The solution he considered was to display an icon representing Leader position 06 and the text of the RDA 338 (carrier), with only the icon displaying in the absence of RDA type data. 
Some have expressed concerns about the adequacy of the RDA vocabularies as a means of serving the GMD purpose of describing "in general terms and at an early point in the description, the class of materials to which the item belongs". Panchyshyn (2014) stated that during Kent State University's involvement in RDA testing it became apparent that removal of GMD was problematic for staff and potentially patrons, and that the controlled values of the RDA type fields were not easily comprehended by users. Cronin (2011) stated that staff at the University Of Chicago also questioned the utility of the RDA type fields, with cataloguer concerns about whether the RDA labels were intuitive for users. McCutcheon's (2012) reference librarians found the terms unintuitive - especially the media types. Arguably, it is unreasonable to expect users to understand that an unmediated resource with a volume carrier and text content is in fact a book.

But working with raw values from these vocabularies is not the only option. As Hider \& Huthwaite (2006) state, the intention of RDA is to provide guidance on representation of bibliographic data, not its presentation on the OPAC. Green and Fallgren (2007) note that whilst "an intuitive expression is key for helping users achieve identification and filtering goals" this can be achieved by "mapping natural language expressions to (combinations of) less intuitive attribute values" (p.90).

SCIS commenced use of the RDA type fields in 2013 but continued to provide the GMD until early 2017 to support user display in certain library systems in popular use in Australian and New Zealand schools. As SCIS moves to a new online platform it is considering use of a seperate vocabulary consisting of user-friendly type (UFT) descriptors. SCIS subscribers use its database to find, select, and identify records for resources (but not to locate items), and a UFT vocabulary could be used to facilitate each of these tasks. Vocabulary values could be mapped from existing values in MARC records, thereby achieving Panchyshyn's (2014) objective of providing consistent type description over AACR2, RDA and hybrid records.

Given questions over the intuitiveness of type descriptors in GMD and RDA, the purpose of this paper is to explore possible labels for such a UFT vocabulary. For a small set of digital/electronic resources, school library staff were asked to rate at least one UFT label in contrast with the GMD and RDA labels for the same resource type.

Supplementing an ambiguous or uni-dimensional type description with parenthetic qualifiers may improve clarity and increase user friendliness (Guerrini, 2004; Hider, 2009b). The ANSI/NISO (2005) Z39.19 standard recommends use of parenthetical qualifiers to disambiguate homographs, though recommends against their use if an appropriate compound term is available (eg Digital music versus Music (Digital)). In the current study, the acceptability of parenthetical qualifiers in labels was also evaluated, and whether it is generally more acceptable to qualify the content or carrier/format of the resource.

Finally, following from research such as Hider (2009), Ou and Saxon (2014) and Panchyshyn (2014), the current study was interested in whether participants demonstrated any preference for representing type via RDA content (MARC 336), RDA carrier (MARC 338), or a combination of the two. Research questions

The current paper examined four specific questions relating to the description of resource type for nine categories of electronic/digital resources:

1. Do school library staff prefer the UFT labels over those offered by GMD or RDA?

2. Do they demonstrate preferences around use of qualifiers in those items containing UFT options with both qualified and unqualified versions?

3. In those items containing UFT options with qualified versions, do respondents demonstrate a preference for content-based labels qualified by format, or format-based labels qualified by content?

4. Finally, do respondents demonstrate preferences for RDA content, RDA carrier, or a combination of both?

For each of these questions, secondary interest was also given to whether subgroups of respondents differed in their preferences, as defined by their role in the library and the size, sector and level of their school. 


\section{METHOD}

The SCIS School Library Resourcing survey was conducted on the surveymonkey.com platform between 26 April and 31 May 2016. The survey was promoted through social media, on the SCIS website, and via an email campaign to SCIS subscribers. An AU $\$ 250$ book voucher was offered as a prize to one respondent. Raw data contained identifying information in order to assign the prize. That data was also used to remove multiple responses from the same school before being deleted from the dataset.

The full survey contained 38 items. The current study is primarily concerned with Questions seven to fifteen, though the first six questions are reported for the purpose of describing the respondents (see Appendix A).

Initial questions enquired about the respondent's role in the school (Q1), school enrolment (Q2), school level (Q3), school sector (Q4), school location (Q5), and library staffing (Q6).

Questions seven to fifteen provided a description of a resource type, but avoided use of common labels for that type of item. They also provided an image to indicate the item type. Respondents were asked to select one option indicating which they believe best describes the item for their students. For each item, options were derived from the GMD vocabulary, RDA content type, RDA carrier type, and both RDA content and carrier type combined, and one or more UFT values. Were applicable, more than one UFT option was provided to evaluate preferences for different labels and regarding use of parenthetic qualifiers versus no qualifier. For items with a qualified UFT, options were offered in which the qualifier described content type and in which qualifiers described format. These questions were mandatory and the ordering of options was set to vary randomly.

The different items and the various options provided for each are displayed in Tables Table 8 to Table 16.

\section{Respondents}

An initial response was received from 1434 respondents. Data was removed if respondents did not complete the full survey. If more than one response came from the same school library (as indicated by IP address and details provided by respondents) only one response was retained, firstly from teacher librarians, then librarians, followed by library technicians, then by any other person working in the library. Responses were removed if the option "Other" was selected for school sector, level or location (Questions 3 to 5). The final dataset consisted of 1212 respondents.

\section{Analysis}

All analyses were performed in SPSS Version 24 (IBM, 2016).

For each analysis, a within-subject analysis of variance (ANOVA) tests was conducted to test for a main effect. Marginal means for each analysis are displayed in Table 3. Where more than one category was being compared, these were followed up by post-hoc pairwise Bonferroni adjusted comparisons to identify where differences lay. Next, for the most endorsed category, a series of between-group ANOVAs were performed to examine differential responses between the respondent categories of school level, school sector, respondent role, and school size. School size was dichotomised as large (over 800 enrolments) and small (under 801). For respondent role, the less prevalent (see below) categories of Parent or volunteer, IT Staff, Principal/Assistant Principal, and Teacher were classified as 'Other'. Again, specific differences between more than two categories were examined with post-hoc pairwise Bonferroni adjusted comparisons. 


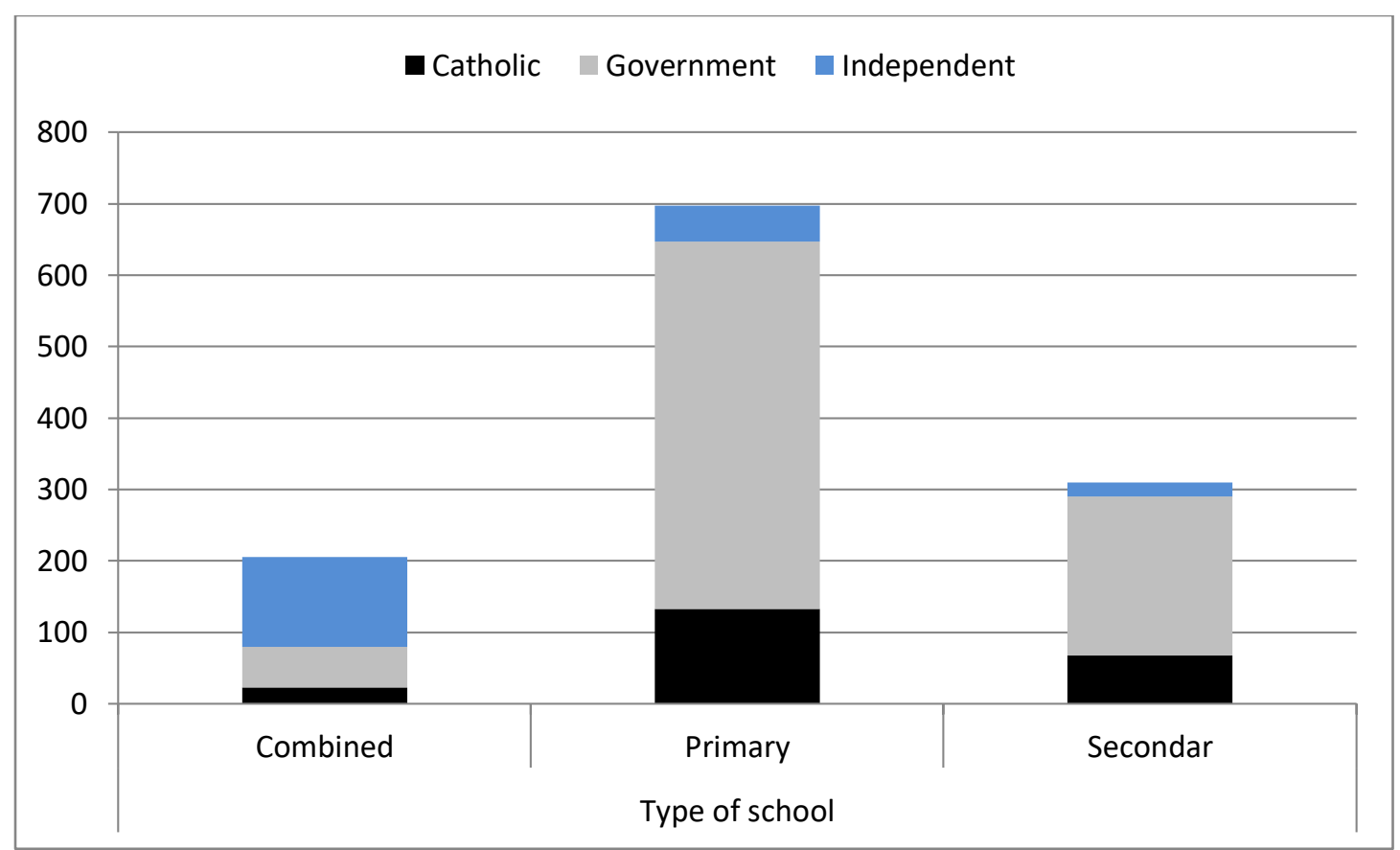

Figure 2. Respondent's school sector and level

Finally, a series of Chi-square analyses were conducted to identify differential preferences on a per-question basis.

\begin{tabular}{|c|c|c|c|}
\hline $\begin{array}{l}\text { Library } \\
\text { Staff }\end{array}$ & Frequency & Percent & $\begin{array}{l}\text { Cumulative } \\
\text { Percent }\end{array}$ \\
\hline 1 & 345 & $28.46 \%$ & $28.46 \%$ \\
\hline 2 & 467 & $38.53 \%$ & $66.99 \%$ \\
\hline 3 & 303 & $25 \%$ & $91.99 \%$ \\
\hline 4 & 54 & $4.45 \%$ & $96.45 \%$ \\
\hline 5. & 28 & $2.31 \%$ & $98.76 \%$ \\
\hline 6 & 15 & $1.23 \%$ & $100 \%$ \\
\hline Total & 1212 & $100 \%$ & \\
\hline
\end{tabular}

\section{Respondents}

\section{RESULTS}

Responses were received from all Australian states and territories - predominantly New South Wales (23.8\%), Victoria (22.5\%), and Queensland (14.6\%), followed by Western Australia (12.3\%) and South Australia (7.7\%). This distribution is roughly representative of population and school distribution across the country. Respondents from New Zealand accounted for $15.8 \%$ of the sample. 
Table 2 Example of how responses to five items were scored in analyses one to four Response

\begin{tabular}{|c|c|c|c|c|c|c|c|}
\hline \multirow[b]{2}{*}{ Analysis } & \multirow[b]{2}{*}{ Category } & \multirow{2}{*}{$\begin{array}{l}7 \\
\text { DVD }\end{array}$} & \multirow{2}{*}{$\begin{array}{l}8 \\
\text { Electronic } \\
\text { Resource }\end{array}$} & \multirow{2}{*}{$\begin{array}{l}9 \\
\text { Musical } \\
\text { Recording }\end{array}$} & \multirow{2}{*}{$\begin{array}{l}10 \\
\text { MP3 } \\
\text { (Music) }\end{array}$} & \multirow{2}{*}{$\begin{array}{l}11 \\
\text { Audiobook } \\
\text { (CD) }\end{array}$} & \multirow[t]{2}{*}{ Value } \\
\hline & & & & & & & \\
\hline \multirow[t]{3}{*}{1} & UFT & $Y$ & & & $Y$ & $Y$ & 0.6 \\
\hline & RDA & & & $Y$ & & & 0.2 \\
\hline & GMD & & $Y$ & & & & 0.2 \\
\hline \multirow[t]{2}{*}{2} & Qualified & & - & - & $Y$ & $Y$ & 0.66 \\
\hline & Unqualified & $Y$ & - & - & & & 0.33 \\
\hline \multirow[t]{2}{*}{3} & Format & - & - & - & & $Y$ & 0.5 \\
\hline & Content & - & - & - & $Y$ & & 0.5 \\
\hline \multirow[t]{3}{*}{4} & Content & - & - & $Y$ & - & - & 1 \\
\hline & Carrier & - & - & & - & - & 0 \\
\hline & Both & - & - & & - & - & 0 \\
\hline
\end{tabular}

Responses were predominantly from primary schools (57.5\%), followed by secondary $(25.6 \%)$ and combined schools (16.9\%). Government schools were the highest responders $(65.4 \%)$, followed by Catholic (18.5\%) and Independent schools (16.1\%). As seen in Figure 2, the largest sub-group of respondents was Government primary schools (37.4\% of total responses), followed by Government secondary $(15.9 \%)$ and Independent combined $(11.1 \%)$ schools.

Thirty-two percent of respondents were Teacher Librarians, followed by administrative/support staff (21.9\%), library technicians (20.2\%) and librarians (19.2\%). Other roles accounted for only $7 \%$ or responses.

Fifteen percent of responses came from schools with fewer than 200 enrolments. The largest proportion of responses $(35.6 \%$ ) came from schools with 401 to 800 enrolments, and only $8.7 \%$ had more than 1200 enrolments.

\begin{tabular}{lcccc}
\multicolumn{4}{l}{ Table 3} & Marginal means for Analyses One to Four \\
\hline \hline Analysis & & 3 & 4 & Responses \\
1 & 2 & 3 & .679 \\
\hline UFT & & & .308 \\
& Unqualified & .692 \\
& Qualified & & .389
\end{tabular}


The reported number of full time equivalent roles in the library can be seen in Table 1 . Only $8 \%$ of respondents had more than three staff, and almost one third reported having a single staff member.

\section{Analysis 1: UFT, RDA and GMD}

To assess preferences for vocabulary, responses were classified as either UFT, RDA, or GMD. An example of the scoring methodology can be found in

Table 2. A per-person score for each vocabulary was obtained by calculating their response to each as a proportion of all items they responded to (in the example, for UFT $3 / 5=0.6$ ). The interpretation of this score is the respondent's proportional endorsement of the category (in the example, the respondent demonstrated $60 \%$ endorsement of the UFT values).

A within-subjects ANOVA comparing user's proportional ratings of UFT, GMD and RDA terms found a significant main effect, $\mathrm{F}(2,2422)=4160.614, \mathrm{p}<.001$. Comparisons revealed that ratings for UFT (mean $=0.679$ ) were significantly higher than RDA (mean=0.176; $\mathrm{p}<.001$ ), which were in turn higher than ratings for GMD (mean $=0.145 ; \mathrm{p}<.001)$.

Four separate one-way ANOVAs were performed to examine the separate impact of role, school size, school level, and school sector on UFT ratings. Marginal means for these analyses can be found in

Table 4. A main effect was found for role, $\mathrm{F}(4,1207)=4.271, \mathrm{p}=.002$, with comparisons revealing that TLs approved of UFT more than librarians, library technicians, and school administrators. No main effects were found for school size $(\mathrm{F}(1,1210)=.5, \mathrm{p}=\mathrm{ns})$, level $(\mathrm{F}(2,1209)=.564, \mathrm{p}=\mathrm{ns})$, or sector $(\mathrm{F}(2,1209)=2 \cdot 12, \mathrm{p}=\mathrm{ns})$.

\section{Table 4 Responses to UFT in Analysis One, by Respondent Characteristics}

\begin{tabular}{lll}
\hline \hline & & Responses \\
\hline School level & Primary & 0.680 \\
& Secondary & 0.672 \\
& Combined & 0.686 \\
School sector & Government & 0.673 \\
& Catholic & 0.688 \\
& Independent & 0.694 \\
School size & Small (<801 enrolments) & 0.679 \\
& Large (>800 enrolments) & 0.681
\end{tabular}


Respondent's Teacher librarian

role 0.704

Librarian $\quad 0.675$

Library technician $\quad 0.662$

Admin/Support $\quad 0.664$

Other $\quad 0.675$

$\begin{array}{ll}\text { Total } & 0.679\end{array}$

\section{Analysis 2: Qualifiers in UFTs}

To assess preferences for qualifiers, responses to UFT options were classified as either qualified or unqualified. An example of the scoring methodology can be found in

Table 2. A per-person score for each category was obtained by calculating their response to each as a proportion of all UFT items they responded to (in the example, for qualified, $2 / 3=0.66$ ).

A within-subjects ANOVA comparing qualified to unqualified UFT labels found a significant effect $(\mathrm{F}(1,1203)=520.429, \mathrm{p}<.001)$, with qualified (mean=0.692) being endorsed more than unqualified (mean=0.308).

Between-subject one-way ANOVAs comparing ratings of qualified labels found significant main effects for school size $(\mathrm{F}(1,1202)=10.21, \mathrm{p}=.001)$, level $(\mathrm{F}(2,1201)=9.141, \mathrm{p}<.001)$ and sector $(\mathrm{F}(2,1201)=4.22, \mathrm{p}=.015)$. Marginal means for these analyses can be found in Table 5. Comparisons found that small schools (mean=.706) endorsed qualified labels more than large schools (mean=.643), primary schools $($ mean $=.72)$ showed greater endorsement than combined (mean=.626,p<.001), and government (mean=.705) more endorsement than independent (mean=.637, $\mathrm{p}=.011)$.

No main effect was found for role $(\mathrm{F}(4,1199)=1.139$, $\mathrm{p}=$ n.s. $)$.

Table 5 Responses to Qualified UFT in Analysis Two, by Respondent Characteristics

Responses

$\begin{array}{lll}\text { School level } & \text { Primary } & 0.720 \\ & \text { Secondary } & 0.673 \\ \text { School sector } & \text { Gombined } & 0.626 \\ & \text { Catholic } & 0.705 \\ & \text { Independent } & 0.694 \\ \text { School size } & \text { Small (<801 enrolments) } & 0.706 \\ & \text { Large (>800 enrolments) } & 0.643 \\ \text { Respondent's role } & \text { Teacher librarian } & 0.668 \\ & \text { Librarian } & 0.700\end{array}$


Library technician

Admin/Support

Other

Total
0.691

0.712

0.717

0.692

\section{Analysis 3: Label vs Qualifier for Qualified UFTs}

To assess preferences for content or format qualifiers, responses to UFT options with qualifiers were classified as either content or format. An example of the scoring methodology can be found in

Table 2. A per-person score for each category was obtained by calculating their response to each as a proportion of all qualified UFT items they responded to (in the example, for format, $1 / 2=0.5$ ).

A within-subjects ANOVA comparing content versus format as qualifier found a significant effect $(\mathrm{F}(1,1146)=108.466, \mathrm{p}<.001)$, with format-as-qualifier (mean $=.611)$ being more highly endorsed than content $($ mean $=.389)$.

Between-subject ANOVAs comparing ratings of content qualifiers found significant main effects for level $(\mathrm{F}(2,1144)=8.294, \mathrm{p}<.001)$ and size $(\mathrm{F}(1,1145)=4.904, \mathrm{p}=.027)$. Marginal means for these analyses can be found in Table 6. Comparisons found that large schools (mean=.653) endorsed format as a qualifier more than small schools (mean=.598), and both secondary (mean=.653) and combined schools $($ mean $=.671)$ showed greater endorsement than primary schools $($ mean $=.574, \mathrm{p}<.014)$.

\section{Analysis 4: RDA}

No main effects were found for sector $(\mathrm{F}(2,1144)=.573$, $\mathrm{p}=\mathrm{n}$.s. $)$ or role $(\mathrm{F}(4,1142)=.088$, $\mathrm{p}=\mathrm{n}$.s. $)$.

To assess preferences for RDA types, responses to RDA options were classified as either content, carrier, or both. An example of the scoring methodology can be found in

Table 2. A per-person score for each category was obtained by calculating their response to each as a proportion of all RDA items they responded to (in the example, for content, 1/1=1).

Table 6 Responses to Format-Qualified UFT in Analysis Three, by Respondent Characteristics

\begin{tabular}{lll}
\hline & & Responses \\
\hline School level & Primary & .574 \\
& Secondary & .653 \\
& Combined & .671 \\
School sector & Government & .609 \\
& Catholic & .597 \\
School size & Independent & .635 \\
& Small (<801 enrolments) & .598 \\
Respondent's role & Teacher librarian & .653 \\
& Librarian & .614
\end{tabular}




$\begin{array}{ll}\text { Library technician } & .611 \\ \text { Admin/Support } & .615 \\ \text { Other } & .615\end{array}$

Total $\quad .611$

A one-way within-persons ANOVA was significant $(F(2,1990)=412.721, p<.001)$, with comparisons revealing that Content $(m e a n=0.04)$ was endorsed less frequently than either Carrier (mean= $0.587, \mathrm{p}<.001)$ or Both $($ mean $=.373, \mathrm{p}<.001)$. Carrier was also endorsed more frequently than Both $(\mathrm{p}<.001)$.

Four separate one-way ANOVAs were performed to examine the separate impact of role, school size, school level, and school sector on RDA Carrier ratings. Marginal means for these analyses can be found in Table 7. A main effect was found for sector $(\mathrm{F}(2,993)=3.312, \mathrm{p}=0.037)$, with comparisons revealing that independent schools (mean=.669) were more approving of RDA Carrier than government schools (mean=..575, $\mathrm{p}=.044)$. A main effect was also found for school level $(\mathrm{F}(2,993)=4.344, \mathrm{p}=.013)$, with comparisons revealing that combined schools (mean=.669) were more supportive of RDA carrier type than primary schools (mean=.561, $\mathrm{p}=.012$ ). No main effects were found for role, $\mathrm{F}(4,991)=0.07, \mathrm{p}=\mathrm{n}$.s., or school $\operatorname{size}(\mathrm{F}(1,994)=.003, \mathrm{p}=\mathrm{n} . \mathrm{s}$. $)$.

Preferences Per Item

Tables Table 8 to Table 16 display raw responses on a per-item basis. Chi-square testing revealed significant differences in response rate for all nine items. 
Table 7 Responses to RDA Carrier in Analysis Four, by Respondent Characteristics

\begin{tabular}{lll}
\hline \hline & & Responses \\
\hline School level & Primary & .561 \\
& Secondary & .601 \\
& Combined & .669 \\
School sector & Government & .575 \\
& Catholic & .565 \\
School size & Independent & .669 \\
& Small (<801 enrolments) & .587 \\
Respondent's & Large (>800 enrolments) & .586 \\
& Teacher librarian & .585 \\
& & .600 \\
& Librarian & .589 \\
& Library technician & .563 \\
& Admin/Support & .626 \\
& Other & .587
\end{tabular}

In question seven the overwhelming majority of respondents favoured the UFT option "DVD" (Chi-sq (4) =4268.49, p<.001).

Table 8 Raw responses to Question 7

\begin{tabular}{|c|c|c|c|}
\hline Category & & Item & Response \\
\hline UFT & & DVD & 1152 \\
\hline GMD & & Videorecording & 32 \\
\hline \multirow[t]{3}{*}{ RDA } & Carrier & Videodisc & 14 \\
\hline & Content & Moving image & 2 \\
\hline & Both & Videodisc, moving image & 12 \\
\hline
\end{tabular}

In Question Eight the majority of respondents endorsed RDA, and carrier type in particular (Chisq $(5)=794.32, \mathrm{p}<.001)$. 
Table 9 Raw responses to Question 8

\begin{tabular}{|c|c|c|c|}
\hline Category & & Item & Response \\
\hline UFT & & Digital video & 283 \\
\hline \multirow[t]{2}{*}{ GMD } & & Videorecording & 50 \\
\hline & & Electronic resource & 140 \\
\hline \multirow[t]{3}{*}{ RDA } & Carrier & Online resource & 494 \\
\hline & Content & Moving image & 2 \\
\hline & Both & Online resource, moving image & 243 \\
\hline
\end{tabular}

UFT values were the most highly endorsed in Question Nine, with format qualified by content $(\mathrm{CD}$ (Music)) receiving the most ratings (Chi-sq (6) $=1130.2, \mathrm{p}<.001)$.

Table 10 Raw responses to Question 9

\begin{tabular}{llll}
\hline \hline Category & & Item & Response \\
\hline UFT & Unqualified & CD & 378 \\
& Qualified by format & Music (CD) & 196 \\
& Qualified by content & CD (Music) & 463 \\
GMD & & Sound recording & 63 \\
RDA & Carrier & Audio disc & 49 \\
& Content & Musical recording & 4 \\
& Both & Audio disc, musical & 59
\end{tabular}

In Question Ten, UFT was more highly rated than RDA or GMD (Chi-sq (10) $=383.34, \mathrm{p}<.001$ ). Whilst UFT qualified by content (MP3(Music)) was the single item receiving the most raw ratings, UFT qualified by format received more ratings in total when consolidated over two items, with Music (Digital) being the most highly rated of those. 


\begin{tabular}{llll}
\hline Category & & Item & Response \\
\hline UFT & Unqualified & Digital audio & 86 \\
& & Digital music & 175 \\
& Qualified by format & MP3 & 134 \\
& & Music (MP3) & 154 \\
& Qualified by content & MP3 (Music) & 180 \\
GMD & Sound recording & 201 \\
& & Electronic resource & 67 \\
RDA & Carrier & Online resource & 29 \\
& Content & Musical recording & 11 \\
& Both & Online resource, musical & 123 \\
& & recording &
\end{tabular}

UFT qualified by format (Audiobook(CD)) was the single item receiving most ratings in Question 11 (Chi-sq (6) =2441.35, p<.001).

Table 12 Raw responses to Question 11

\begin{tabular}{llll}
\hline Category & & Item & Response \\
\hline UFT & Unqualified & CD & 43 \\
& Qualified by format & Audiobook (CD) & 726 \\
& Qualified by content & CD (Audiobook) & 313 \\
GMD & & Sound recording & 37 \\
RDA & Carrier & Audio disc & 54 \\
& Content & Spoken word & 2 \\
& Both & Audio disc, spoken & 37
\end{tabular}

In Question 12, the unqualified UFT item (e-book) received the highest number of raw ratings (Chi-sq $(6)=1387.42, \mathrm{p}<.001$ ). However, in composite the qualified options were endorsed more highly, with the UFT value qualified by format (e-book (online)) being the most highly rated of them. 
Table 13 Raw responses to Question 12

\begin{tabular}{llll}
\hline \hline Category & & Item & Response \\
\hline UFT & Unqualified & e-book & 466 \\
& Qualified by format & e-book (online) & 443 \\
& Qualified by content & $\begin{array}{l}\text { Online resource (e- } \\
\text { book) }\end{array}$ & 176 \\
GMD & Electronic resource & 27 \\
RDA & Carrier & Online resource & 55 \\
& Content & Text & 1 \\
& Both & Online resource, text & 44
\end{tabular}

Question three contained three unqualified UFT options, with App being the most highly rated of all options (Chi-sq (5) =2380.98, p<.001).

Table 14 Raw responses to Question 13

\begin{tabular}{llll}
\hline Category & & Item & Response \\
\hline UFT & & App & 831 \\
& & Mobile application & 98 \\
GMD & Carrier & Electronic resource & 104 \\
RDA & Content & Online resource & 99 \\
& Both & Computer program & 10 \\
& & Online resource, & 70
\end{tabular}

The single UFT option, Website, was the most endorsed item in Question 14 (Chi-sq (4) $=1769.52, \mathrm{p}<.001)$. 
Table 15 Raw responses to Question 14

\begin{tabular}{llll}
\hline Category & & Item & Response \\
\hline UFT & & Website & 828 \\
GMD & & Electronic Resource & 101 \\
RDA & Carrier & Online resource & 164 \\
& Content & Text & 3 \\
& Both & Online resource, & 116 \\
& & text &
\end{tabular}

The single UFT option, CD-ROM, was the most endorsed item in Question 15 (Chi-sq (4) $=2296.35, \mathrm{p}<.001)$.

Table 16 Raw responses to Question 15

\begin{tabular}{llll}
\hline \hline Category & & Item & Response \\
\hline UFT & & CD-ROM & 909 \\
GMD & & Electronic resource & 83 \\
RDA & Carrier & Computer disc & 87 \\
& Content & Computer program & 46 \\
& Both & Computer disc, & 87
\end{tabular}

\section{DISCUSSION}

The current paper examined items from the 2016 SCIS School Library Resourcing survey to determine the kinds of resource type labels school library staff felt best represented a set of electronic and digital resources for their end users. In 2017 SCIS ceased cataloguing the GMD after four years of creating hybrid AARC2/RDA records, and, coinciding with a new online platform in 2017, faces decisions about how best to represent resource types for the purpose of enabling its subscribers to find, identify, and select records in its online database.

Whilst the categories offered by GMD were unwieldy for describing contemporary resource types, it did provide a single, straightforward way "to indicate, in general terms and at an early point in the description, the class of materials to which the item belongs" (Guerrini, 2004).

The RDA content, media, and carrier type fields provide a more flexible facetted description of type, but the interpretation of the RDA labels and use of the facets may not be intuitive to users (McCutcheon, 2012; Hider, 2009). Libraries and systems also struggle to know if and how to represent resource type based on the RDA dimensions (Ou and Saxon, 2014; Panchyshyn, 2014).

One option, suggested by Green and Fallgren (2007) and considered by SCIS, is to map a separate, user-friendly type (UFT) vocabulary to existing MARC data, irrespective of whether that data comes from the GMD, MARC control fields, or RDA type fields.

The current study was conducted as a first step in this process - to evaluate school library staffs' response to possible UFT terms as opposed to GMD or RDA values for a set of commonly held digital/electronic resources. To improve the clarity and user-friendliness of labels, use of parenthetic 
qualifiers of content type or format was also considered, as suggested by the ANSI/NISO (2005) Z39.19 standard.

Overall, the UFT labels were strongly favoured by school library staff, being endorsed on an average of almost $70 \%$ of items. This was true across all respondent subgroups, however Teacher Librarians appeared even more enthusiastic about UFT descriptions. Per-item analyses confirmed the general finding: with the exception of one item, UFT labels were the most highly rated for all items.

This finding is consistent with views that both GMD and RDA terms can be inadequate or unintuitive as a description for these types of resources (eg Hider, 2009).

When it came to qualifiers, the qualified form of UFT labels was endorsed more than twice as often as an unqualified version, and this was found consistently across all four items with qualified versions. Whilst the qualified form of UFTs was endorsed by all subgroups, small schools, primary schools, and government schools demonstrated a particular preference. Government primary schools, the most prominent subgroup in the survey, may appreciate the greater clarify afforded by qualifiers for their students who are able to read but still consolidating their cognitive schema for understanding resources and how they are classified and organised.

Analysis three was concerned with the nature of parenthetic qualifiers: did respondents prefer content-type descriptions to be qualified by format descriptions, or visa versa. Format-based qualifiers were endorsed in, on average, $61 \%$ of corresponding items. In only one item did respondents prefer a content-based qualifier, "CD (Music)" as opposed to "Music (CD)". The reason for this preference is not clear when the format-based qualifier was preferred in analogous items such as "Audiobook (CD)". It may be related to ambiguity over the term "Music" and its association with printed/notated music. Whilst all subgroups preferred format-based qualifiers on the whole, they were particularly endorsed by large, secondary and combined schools.

Next to UFT terms, the greatest endorsement was for RDA values. Within that category, users preferred the carrier type value (MARC 338) on its own (endorsed in nearly 60\% of RDA items on average), followed by a combination of both content and carrier type (37\% of RDA items on average). In fact, for one item, a digital video, RDA was endorsed more than UFT values and the RDA Carrier type ("Online Resource") was the single most endorsed item. Perhaps in the case of online videos, it is not clear to end-users that the video component can be clearly considered in isolation from the rest of the webpage, which can be rich in text and images. Alternatively, this finding may have been an artefact of the particular description used for this item, or the image used to convey it. This concern could be equally true of any item in the current study, where only one item was chosen to represent each "type". In this sense, the current findings could benefit from replication with a larger item set.

Nevertheless, the size of the responses observed, their general consistency over items, and their consistency over subgroups of schools and library roles (which differed a little in emphasis but not core findings), argues for the strength of the conclusions. The findings strongly support the role for a UFT vocabulary in describing resources in the SCIS database. The current findings suggest that school library staff believe that user-friendly terms can, on the whole, be usefully supplemented by format-based qualifiers to describe resource types for K-12 students and their teachers.

Subsequent work will be needed to establish the scope of such a vocabulary: what types of resources are used consistently across schools, or used occasionally in enough schools to warrant inclusion in a vocabulary. Existing SCIS knowledge about the kinds of records downloaded from the service may contribute to this (Chadwick, 2017).

A further question is the degree to which such a vocabulary is constrained by the available values in MARC records, as provided by the GMD, control fields, RDA fields, and other uncontrolled MARC fields. Can the vocabulary reasonably contain values that cannot be mapped from existing MARC data.

Having established resource type concepts with appropriately user-friendly labels, the next challenge will be to determine and optimize an algorithm for consistently and accurately mapping data from AARC2, hybrid, and RDA records to vocabulary values.

Once a system can be trusted to convert MARC records, despite their vintage, to a consistent, user-friendly, and future-oriented vocabulary of resource type descriptions, such a vocabulary could be 
put to use in improving search, selection, and identification of resources for SCIS subscribers seeking to provide the best resources for the teachers and learners in their schools.

\section{REFERENCES}

American National Standards Institute and National Information Standards Organization (2005). Z39.19Guidelines for the Construction, Format, and Management of Monolingual Controlled Vocabularies, Maryland, USA: National Information Standards Organization

Australian Library and Information Association (2015). 80:20 by 2020. Deakin, ACT: Australian Library and Information Association. Retrieved 8 May 2017 from https://www.alia.org.au/sites/default/files/documents/ALIA-8020-by-2020.pdf

Carlyle, A. (1999). User categorisation of works: Toward improved organisation of online catalogue displays. Journal of documentation, 55(2), 184-208.

Chadwick, B. (2017). How are you using SCIS? Connections, 103, 10-11.

Cronin, C. (2011). From testing to implementation: Managing full-scale RDA adoption at the University of Chicago. Cataloging \& Classification Quarterly, 49(7-8), 626-646.

Domingo, M. G., \& Gargante, A. B. (2016). Exploring the use of educational technology in primary education: Teachers' perception of mobile technology learning impacts and applications' use in the classroom. Computers in Human Behavior, 56, 21-28.

Green, R., \& Fallgren, N. (2007). Anticipating new media: A faceted classification of material types. Proceedings of the North American Symposium on Knowledge Organization. 1, 87-99.

Guerrini, M. (2004). GMD: Its function and its history. Cataloging \& Classification Quarterly, 38(2), 6174.

Hider, P. (2009). A Comparison Between the RDA Taxonomies and End-User Categorizations of Content and Carrier, Cataloging \& Classification Quarterly, 47(6), 544-560

Hider, P., \& Huthwaite, A. (2006). The potential impact of RDA on OPAC displays. In Proceedings of Beyond the OPAC: Future Directions for Web-based Catalogues: Australian Committee on Cataloging Seminar, Perth, Australia, 18 September 2006. Retrieved 8 May 2017 from https://shop.nla.gov.au/lis/stndrds/grps/acoc/documents/Hider_Huthwaite.doc

IBM Corp. (2016). IBM SPSS Statistics for Windows, Version 24.0. Armonk, NY: IBM Corp.

McCutcheon, S. (2012). RDA and the reference librarian: What to expect from the new cataloging standard. The Reference Librarian, 53(2), 123-137.

Niu, X., Zhang, T. and Chen, H.L. (2014). Study of user search activities with two discovery tools at an academic library. International Journal of Human-Computer Interaction, 30(5), 422-433.

O'Connell, J., Bales, J. and Mitchell, P., 2015. [R] Evolution in reading cultures: 2020 vision for school libraries. The Australian Library Journal, 64(3), 194-208.

Oddone, C. (2011). Using videos from YouTube and websites in the CLIL classroom. Kalbu Studijos, 18, $105-110$.

Ou, C., \& Saxon, S. (2014). Displaying content, media, and carrier types in the OPAC: Questions and considerations. Journal of Library Metadata, 14(3-4), 239-254.

Panchyshyn, R. S. (2014). RDA display and the general material designation: An innovative solution. Cataloging \& classification quarterly, 52(5), 487-505.

Softlink (2016), The 2016 Softlink Australian and New Zealand school library survey, Softlink. Retrieved 12 May 2017 from https://www.softlinkint.com/downloads/Australian and New Zealand_School_library_survey_report.pdf 


\section{APPENDIX A - 2016 SCIS School Library Resourcing survey Questions 1 to 15}

Your School and Library

Thank you for taking the time to fill in this survey for the Schools Catalogue Information Service (SCIS). This survey is intended for Australian and New Zealand schools that have a library (resource centre). All results will remain anonymous. This survey will take approximately 10 minutes to complete.

*1. What is your current role?

Teacher Librarian

Librarian

Library technician

$\pi$ statt

Audio-visual staft

School Admin/Support or Bbrary officer

Teacher

Principal/Assistant Principal

Parent or volunteer

Other (please specily)

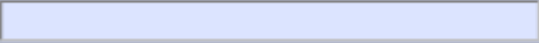

$* 2$. What is the total enrolment at your school?

less than 200 students

201 - 400 students

401 - 800 students

801 - 1200 students

1201 - 1600 students

1601 - 2000 students

more than 2000 students 
* 3. Type of school

(C) Primary

Secondary

Combined Primary/Secondary

Other (please specify)

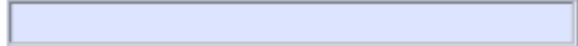

* 4. School sector

(Covemment

Catholic

Independent

Other (please specify)

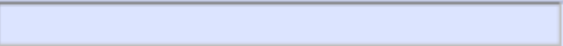

* 5. School location

ACT

NSW

NT

QLD

(CA

C TAS

( vic

(1) WA

New Zealand

Other (please specily)

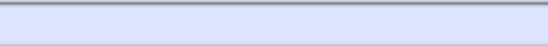


* 6. Who works in the library, including yourself? Please indicate full-time equivalent (FTE) positions for each role, using only full or decimal numbers So, if you had two volunteers working two days per week ( $0.4 \mathrm{FTE}$ each), and one working three days per week (0.6 FTE), you would enter 1.4 next to 'Parents/volunteers'

Teacher Ibrarian

Librarian

Library technician

IT staft

Audio-visual staft

School assistant/ibrary

officer

Teacher

Parent/volunteer

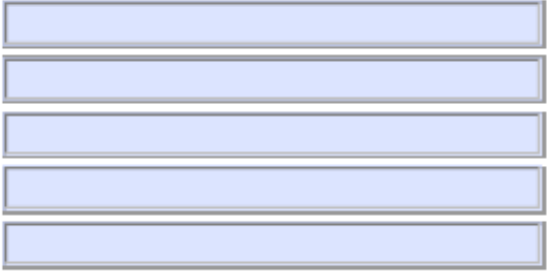

Describing Resources

Part of cataloguing includes describing the 'type' of resource. Resources can be described in a number of ways, and we want to understand which way is most helpful to your students.

* 7. This resource is a movie that is usually viewed by inserting it into a player and watching it on a television. How would you best describe this resource for your students?

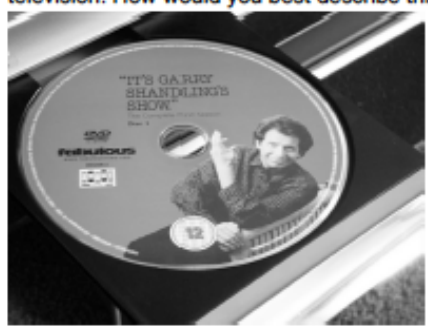

Videorecording

DVD

Videodisc

Moving image

Video disc, moving image 


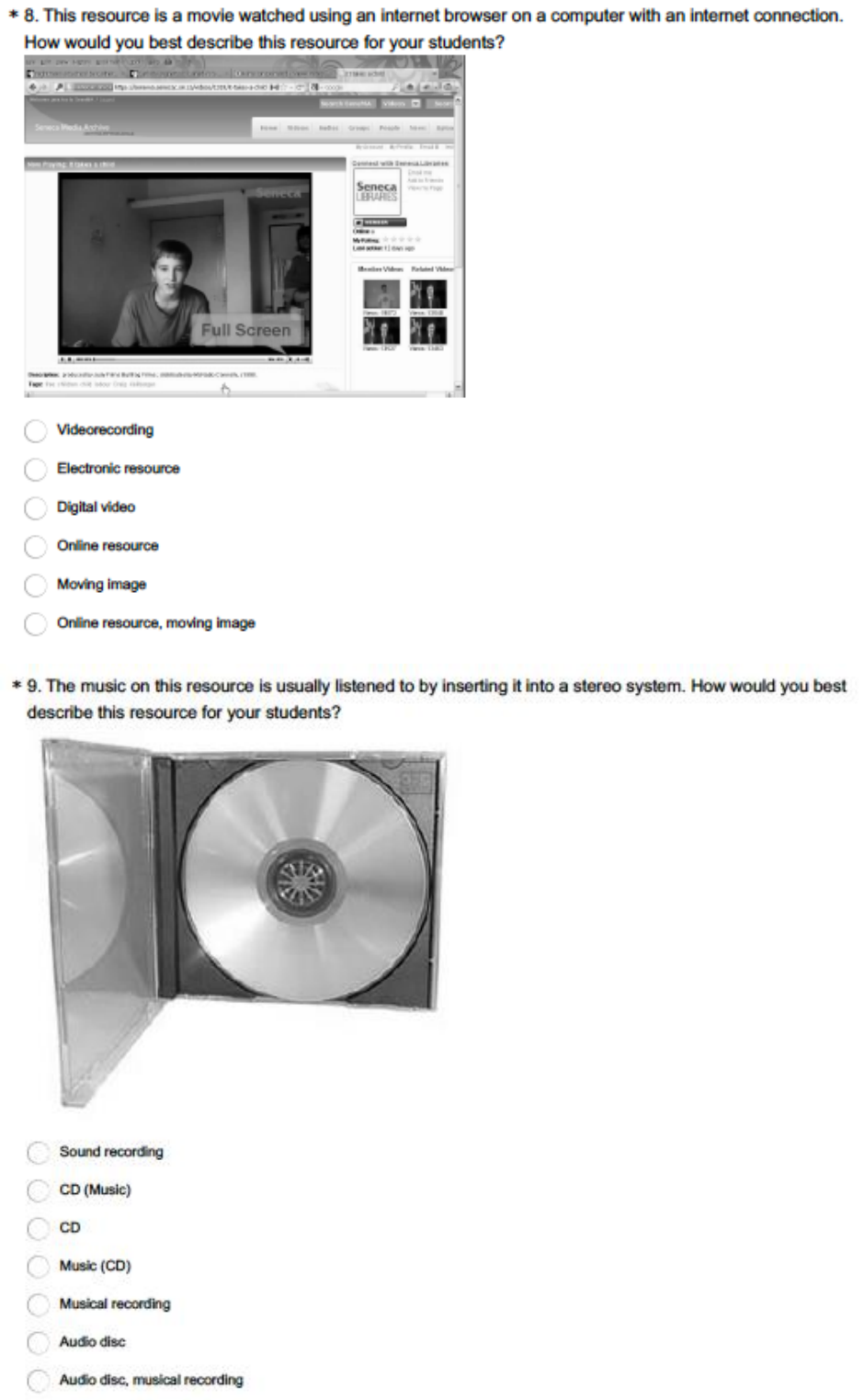


* 10. The music on this downlosdable resource is listened to using computer software or a portable device like an iPod. How would you best describe this resource for your students?

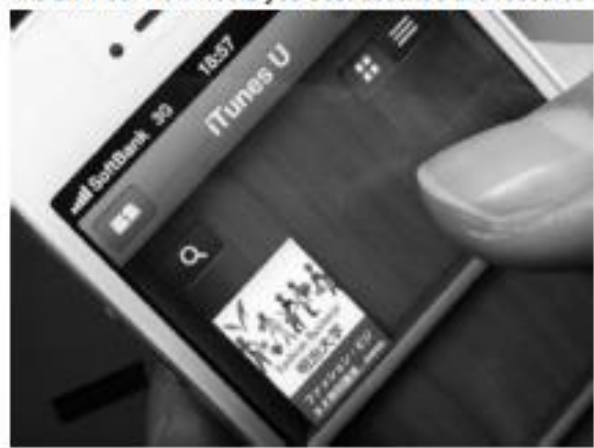
Electronic rascurco
Sound rocording
Digkal maic
MP3
MP3 (muak)
Digkal auso
(1) Muacal reocraing
Online resource
O) Onine resource, Muaical reconding
Muac (MP3)
Maic (Dighal) 
* 11. On this resource an actor reads aloud from a book. It is usually listened to on a stereo system. How would you best describe this resource for your students?

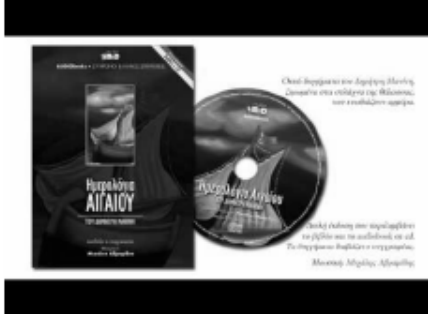

Sound recording

Audiobook (CD)

$\mathrm{CD}$

Spoken word

Audio disc

Audio disc, Spoken word

$\operatorname{CD}$ (Audiobook)

* 12. This book can be read by viewing it online on a vendor's platform. How would you best describe this resource for your students?

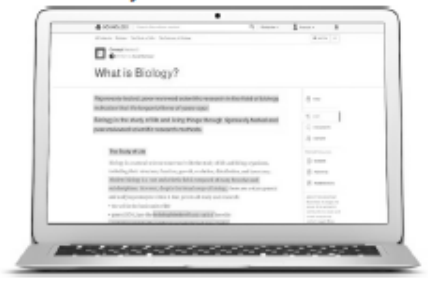

Electronic resource

e-Book (online)

e-Book

Online resource

Text

Online resource, text

Online resource (e-Book) 
* 13. This interactive resource can be used by downloading it from a website and installing it on a portable device like an iPad. How would you best describe this resource for your students?

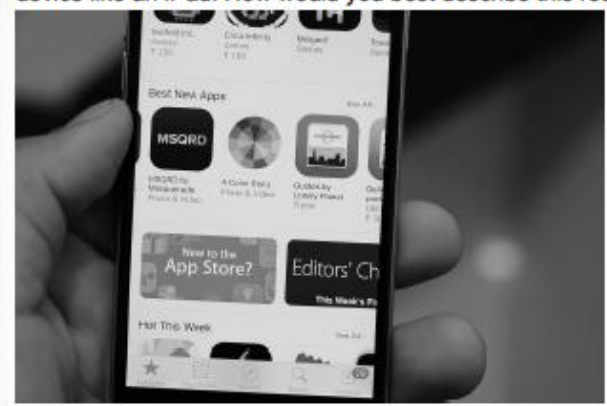

Electronic resource

App

Mobile application

Computer program

Online resource

Online resource, Computer program 
* 14. This resource can be read by visiting a URL on an internet browser. How would you best describe this resource for your students?

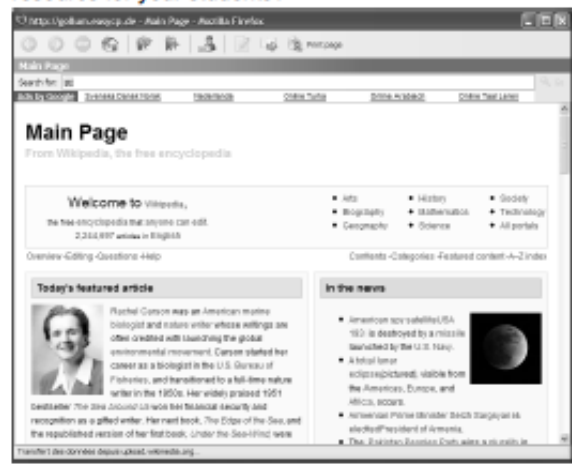
Website
Electronic resource
Onine resource
(Cext
Onllne resource, Text

* 15. This interactive resource is used by placing it in a computer drive. How would you best describe this resource for your students?

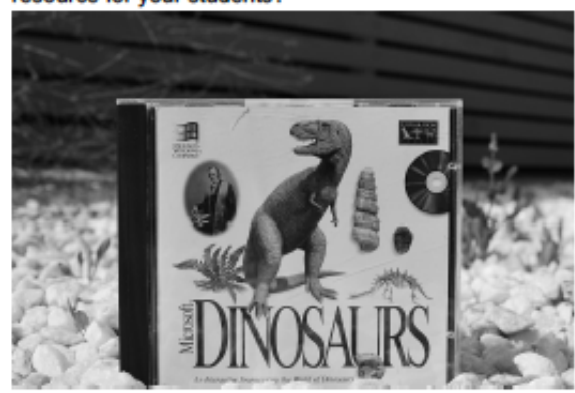
Electronic resource
CD-ROM
Computer disc
Computer program
Computer disc, computer program 